\title{
Re: Small-Cell Neuroendocrine Carcinoma of the Cervix Masquerading as a Cervical Fibroid Report of a rare entity
}

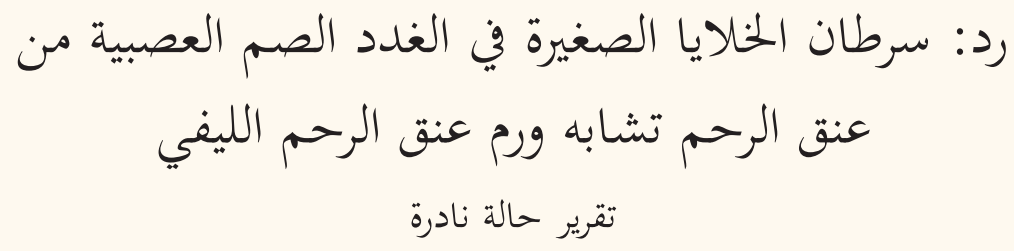

\section{Dear Editor,}

I read with interest the recent case report by Pujani et al. published in the February 2018 issue of SQUMJ in which the authors describe a case of small-cell neuroendocrine carcinoma (SNEC) of the cervix in a 44-year-old Indian woman. ${ }^{1}$ I presume, given the rarity of this condition and the highly aggressive nature of the tumour, the authors have considered that the reported patient may have had an altered immune status. ${ }^{1}$

In India, HIV infection is a sizable health problem, with available data indicating a heightened seroprevalence of $0.26 \%$ compared to the global average of $0.2 \%{ }^{2}$ Among those with altered immune states, HIV status is of the utmost importance. My presumption is based on the fact that HIV-infected patients are more vulnerable to various types of tumours compared to immunocompetent individuals. This increased vulnerability has been attributed to various factors, including suppressed immunity, associated infection with oncogenic viruses and prolonged life expectancy due to antiretroviral treatment. ${ }^{3}$

High rates of cervical cancer have been reported among HIV-infected patients. ${ }^{4}$ Furthermore, genital cancers are found to occur in a substantial proportion of HIV-infected women in India. ${ }^{5}$ Hence, a diagnostic blood workup, cluster of differentiation (CD)4 count and viral overload measurements should have been conducted in order to determine the HIV status of the reported patient. ${ }^{1}$ If the patient was subsequently found to have an HIV infection, the case in question would surely be considered novel as, to the best of my knowledge, HIV-associated SNEC of the cervix has not been reported in the literature to date.

\section{Mahmood D. Al-Mendalawi}

Department of Paediatrics, Al-Kindy College of Medicine, University of Baghdad, Baghdad, Iraq

E-mail:mdalmendalawi@yahoo.com

\section{References}

1. Pujani M, Singh K, Chauhan V, Chawla R, Ahuja R. Small-cell neuroendocrine carcinoma of the cervix masquerading as a cervical fibroid: Report of a rare entity. Sultan Qaboos Univ Med J 2018; 18:e100-3. doi: 10.18295/squmj.2018.18.01.017.

2. Paranjape RS, Challacombe SJ. HIV/AIDS in India: An overview of the Indian epidemic. Oral Dis 2016; 22:10-4. doi: 10.1111/odi.12457.

3. Valencia Ortega ME. Malignancies and infection due to the human immunodeficiency virus: Are these emerging diseases? Rev Clin Esp 2018; 218:149-55. doi: 10.1016/j.rce.2017.07.011.

4. Kohler RE, Tang J, Gopal S, Chinula L, Hosseinipour MC, Liomba NG, et al. High rates of cervical cancer among HIV-infected women at a referral hospital in Malawi. Int J STD AIDS 2016; 27:753-60. doi: 10.1177/0956462415592999.

5. Sharma SK, Soneja M, Ranjan S. Malignancies in human immunodeficiency virus infected patients in India: Initial experience in the HAART era. Indian J Med Res 2015; 142:563-7. doi: 10.4103/0971-5916.171283. 


\section{Response from a Subject Editor}

Dear Reader,

I would like to respond to the above letter to the editor with regards to the aforementioned article by Pujani et al. ${ }^{1}$ Small-cell neuroendocrine carcinoma (NEC) of the cervix is uncommon and accounts for less than $2 \%$ of all cervical cancers. ${ }^{2}$ Although the diagnostic work-up for squamous cell carcinomas (SCCs) or adenocarcinomas of the cervix is very well described, the management plan for a cervical NEC is essentially extrapolated from that of cervical SSC and/or NEC of the lung. Up to 85\% of cervical NEC cases may be caused by the human papilloma virus (HPV), especially strains 16 and 18, with very few case reports implicating HIV in the aetiopathogenesis of this tumour. ${ }^{3,4}$

Overall, NEC is an aggressive cancer in which over 50\% of patients present at an advanced stage; additionally, patients have a poorer prognosis and a higher chance of recurrence compared to those with SCCs or adenocarcinomas of the cervix. ${ }^{5}$ Various factors-including the age of the patient, clinical stage and extent of the disease (i.e. tumour size, parametrial involvement, depth of stromal invasion and lymph node metastasis) and type of treatment (either a radical hysterectomy in the early stages or chemotherapy for advanced disease)-predict survival after treatment. ${ }^{6}$

In their recent study of the molecular characteristics of cervical NEC, Xing et al. suggest that the tumour has an aggressive course. ${ }^{7}$ Whereas high-risk HPV is involved at an early stage of oncogenesis, alterations in the phosphatidylinositol-4,5-bisphosphate 3-kinase catalytic subunit $\alpha, K$-Ras and tumour suppressor p53/breast cancer pathways have been suggested to facilitate the progression of the disease. Other mutations include Erb-B2 receptor tyrosine kinase 2, c-Myc, Notch-1, B-cell lymphoma-6 or nuclear receptor coactivator-3.?

In summary, although SNEC of the cervix is an uncommon cancer, recent research suggests that it follows an aggressive course, regardless of the patient's immune status. ${ }^{6,7}$ Surveillance for HIV is therefore not routinely recommended and should be considered only in cases wherein the patient's clinical features or results of routine serological investigations raise suspicion of the disease.

\section{Ikram A. Burney}

Department of Medicine, Sultan Qaboos University Hospital, Muscat, Oman

E-mail:ikramburney@hotmail.com

\section{References}

1. Pujani M, Singh K, Chauhan V, Chawla R, Ahuja R. Small-cell neuroendocrine carcinoma of the cervix masquerading as a cervical fibroid: Report of a rare entity. Sultan Qaboos Univ Med J 2018; 18: e100-3. doi: 10.18295/squmj.2018.18.01.017.

2. Gardner GJ, Reidy-Lagunes D, Gehrig PA. Neuroendocrine tumors of the gynecologic tract: A Society of Gynecologic Oncology (SGO) clinical document. Gynecol Oncol 2011; 122:190-8. doi: 10.1016/j.ygyno.2011.04.011.

3. Castle PE, Pierz A, Stoler MH. A systematic review and meta-analysis on the attribution of human papillomavirus (HPV) in neuroendocrine cancers of the cervix. Gynecol Oncol 2018; 148:422-9. doi: 10.1016/j.ygyno.2017.12.001.

4. Balega J, Ulbright TM, Look KY. Coexistence of metastatic neuroendocrine carcinoma of the uterine cervix with human immunodeficiency virus infection. Int J Gynecol Cancer 2001; 11:334-7. doi: 10.1046/j.1525-1438.2001.011004334.x.

5. Hou WH, Schultheiss TE, Wong JY, Wakabayashi MT, Chen YJ. Surgery versus radiation treatment for high-grade neuroendocrine cancer of uterine cervix: A Surveillance Epidemiology and End Results database analysis. Int J Gynecol Cancer 2018; 28:188-93. doi: 10.1097/ IGC.0000000000001143

6. Zhang Q, Xiong Y, Ye J, Zhang L, Li L. Influence of clinicopathological characteristics and comprehensive treatment models on the prognosis of small cell carcinoma of the cervix: A systematic review and meta-analysis. PLoS One 2018; 13:e0192784. doi: 10.1371/journal. pone.0192784.

7. Xing D, Zheng G, Schoolmeester JK, Li Z, Pallavajjala A, Haley L, et al. Next-generation sequencing reveals recurrent somatic mutations in small cell neuroendocrine carcinoma of the uterine cervix. Am J Surg Pathol 2018; 42:750-60. doi: 10.1097/PAS.0000000000001042. 